\title{
Pediatric penetrating keratoplasty and graft rejection: experience at the Hospital Infantil de México Federico Gómez
}

\author{
Karen Velásquez-Monzón ${ }^{1}$, Mariana C. Navarro-Peña², Miguel Klunder-Klunder ${ }^{3}$, Michael Tsatsos ${ }^{4}$ y \\ Marco A. Ramírez-Ortiz, 5*
}

${ }^{1}$ Department of Transplant Surgery, Hospital Infantil de México Federico Gómez, Mexico City, Mexico; ${ }^{2}$ Department of Pediatric Ophthalmology, Hospital Infantil de México Federico Gómez, Mexico City, Mexico; ${ }^{3}$ Deputy Direction of Research, Hospital Infantil de México Federico Gómez, Mexico City, Mexico; ${ }^{4}$ Royal Eye Infirmary, Dorset County Hospital NHS Foundation Trust, Dorchester, United Kingdom; ${ }^{5}$ Aristotelian University of Thessaloniki, Greece

\begin{abstract}
Background: Penetrating keratoplasty $(P K)$ is a challenging surgical ocular procedure indicated for some pediatric patients with vision-threatening corneal disease damage. Pediatric PK is reserved for cases with advanced pathology or dysfunction as rejection and failure rates greatly supersede the rates of adult PK. The objective was to identify factors associated with graft rejection and failure amongst Mexican children undergoing primary PK for different indications. Methods: $A$ retrospective review of consecutive pediatric PK medical records was conducted between 2001 and 2015 at the Hospital Infantil de México Federico Gómez. Graft survival was calculated using the Kaplan-Meier survival method. Results: During the 15 years of study, 67 eyes of 57 patients underwent PK. The mean age at the time of surgery was 11 years. The mean follow-up duration was 44 months. Keratoconus was the most common indication for PK (61\%) followed by herpetic keratitis (15\%) and other corneal dystrophies (10\%). Mean graft survival time was 45.6 months (95\% confidence interval 31.8-58.4 months, standard deviation $=0.069)$, with a survival rate of $70 \%$ at 1 year. Univariate Cox proportional hazard showed that being $<9$ years of age at the time of the surgery $(p=0.023)$ and corneal dystrophies $(p=0.04)$ were prognostic factors for corneal rejection. Five eyes of five patients developed graft failure. Conclusions: Pediatric PK patients commonly experience graft rejection, which need to be promptly diagnosed and treated to minimize permanent damage. The age at the time of surgery and congenital corneal opacities is factors associated with a higher risk of rejection and failure.
\end{abstract}

Key words: Penetrating keratoplasty. Graft survival. Organ transplantation. Keratoconus.

\section{Queratoplastia penetrante pediátrica y rechazo corneal: experiencia en el Hospital Infantil de México Federico Gómez}

\section{Resumen}

Introducción: La queratoplastia penetrante (QP) es un procedimiento quirúrgico indicado en algunos pacientes pediátricos con daño corneal con riesgo de fracaso que amenaza la visión. El objetivo del presente trabajo fue identificar los factores asociados a rechazo y fallo del injerto corneal en niños sometidos a QP. Métodos: Serie de casos de pacientes sometidos a QP en el Hospital Infantil de México Federico Gómez entre 2001 y 2015. La sobrevida del injerto fue calculada por el

Correspondencia:

*Marco Antonio Ramírez-Ortiz

E-mail: marco@unam.mx
Disponible en internet: 17-02-2020

Bol Med Hosp Infant Mex. 2020;77(1):23-27

www.bmhim.com 1665-1146/C 2019 Hospital Infantil de México Federico Gómez. Publicado por Permanyer. Este es un artículo open access bajo la licencia CC BY-NC-ND (http://creativecommons.org/licenses/by-nc-nd/4.0/). 
método de estimación de la función de supervivencia Kaplan-Meier. Resultados: Durante 15 años de estudio, 67 ojos de 57 pacientes fueron sometidos a QP. El promedio de edad de los pacientes al tiempo de la cirugía fue de 11 años. El seguimiento promedio fue de 44 meses. El queratocono fue la indicación más común de QP (61\%), seguido de queratitis herpética (15\%) y otras distrofias corneales (10\%). El tiempo promedio de sobrevida fue $45.6 \%$ (intervalo de confianza [IC] 95\%: 31.8-58.4 meses, desviación estándar [DS] = 0.069), con una tasa de sobrevida del $70 \%$ a 1 año. El riesgo proporcional de Cox univariado mostró que una edad $<9$ años al momento de la cirugía $(p=0.023)$ y distrofias corneales $(p=0.04)$ son factores pronóstico para el rechazo corneal. Cinco ojos de cinco pacientes desarrollaron falla del injerto. Conclusiones: $E I$ rechazo del injerto en QP en pacientes pediátricos es común y puede ser resuelto satisfactoriamente en casi todos los casos con diagnóstico y tratamiento. La edad al momento de la cirugía y las opacidades corneales congénitas son factores asociados con el rechazo y fallo.

Palabras clave: Queratoplastia penetrante. Sobrevida del injerto. Trasplante de órganos. Queratocono.

\section{Introduction}

Penetrating keratoplasty (PK) refers to the surgical procedure in which full-thickness cornea is replaced by donated cadaveric corneal tissue. Although many modifications have been added to the PK procedure since the first successful corneal graft performed by Zirm in 1905 in Moravia', PK continues to pose technical and viability/survival challenges in children compared with the same procedure performed in adults. Several factors account for the poorer PK prognosis in children, which are classified as it follows:

1. Pre-operative: Irreversible eye malformations, which will end with guarded visual prognosis and morbidity ${ }^{2}$, leading to deep amblyopia

2. Intraoperative: Technically more difficult surgery due to low scleral rigidity, shallow anterior chamber, and positive vitreous pressure ${ }^{3}$

3.Post-operative: Difficult post-operative communication of reduced visual acuity, suture-related complaints, higher rates of graft rejection, and other post-operative problems such as glaucoma ${ }^{4-7}$.

Hence, a better comprehension of rejection and failure-associated factors can improve futures outcomes.

The objective of this study was to analyze PK graft rejection and graft failure prognostic factors as age at surgery, corneal graft indication (host pathology), and the presence of glaucoma in a tertiary referral pediatric center Hospital Infantil de México Federico Gómez (HIMFG) in Mexico City.

\section{Methods}

The same researcher retrospectively analyzed every pediatric patient who underwent PK between 2001 and 2015 at the HIMFG. The Institutional Review Board and the Ethics Committee approved the study, which was performed following the tenets of the declaration of Helsinki. All donor corneas were obtained through the National Transplant Center coordination (CENATRA: www.gob.mx/cenatra) from different public hospitals. The same researcher evaluated the cases. PK for congenital corneal opacities was indicated when opacity was central over $5 \mathrm{~mm}$ and full corneal thickness; for acquired non-traumatic, when they had best-corrected visual acuity worse than $20 / 80$ or contact lens intolerance, at least 6 months without infectious associated inflammation; for traumatic corneal opacities, after 6 months without inflammatory signs.

Surgical procedures were performed under general anesthesia. Briefly, a Flieringa ring was placed, and a $0.5 \mathrm{~mm}$ oversize graft was used, as well as 10/0 nylon 16 interrupted sutures. Subsequently, careful removal of viscoelastic and a post-operative steroid treatment every $2 \mathrm{~h}$ for 2 weeks was administered, with a slow tapering off regime. Topical prednisolone acetate drops were changed to fluorometholone 6 months postoperatively. All patients had the same post-operative follow-up. Postoperative visits were scheduled as follows: day 1 , after surgery; day 3 , once a week for the $1^{\text {st }}$ month, once a month for the $1^{\text {st }}$ year, every 3 months for the $2^{\text {nd }}$ year, and every 4-6 months for the subsequent years. After each post-operative visit, visual acuity, graft clarity, intraocular pressure, signs of infection or rejection, and suture status were evaluated and reported. Examination under anesthesia was performed when necessary or in uncooperative patients. The suture that loosened before the 4-week post-operative period was replaced. Selective suture removal was done for suture-related problems or visual rehabilitation.

The following variables were retrospectively analyzed: corneal opacity of various etiologies, underlying pathologies, age at the first or second PK, associated ocular surgeries, presence of glaucoma, and coexistence of other eye pathology diseases. PK indications 
in the pediatric population were divided as follows: congenital corneal opacities (corneal dystrophies and anterior segment dysgenesis), acquired non-traumatic (keratoconus, corneal scars from infectious keratitis), and traumatic corneal opacities ${ }^{3}$.

Corneal graft rejection may occur in any corneal layer, and even several during the life-span of the patient, although it is known to be more common during the $1^{\text {st }}$ years after surgery. Clinical findings include epithelial or endothelial rejection line, stromal inflammation band, anterior chamber reaction, keratic precipitates, and increased corneal thickness. If it is diagnosed in early stages and treated appropriately, it could be free of sequels and graft transparency could be achieved, even though the patient has had more than one episode ${ }^{3,8,9}$. Graft failure is common after an episode of rejection, mostly when it was not diagnosed in the early stages or was defined as the irreversible loss of central graft clarity, despite systemic and topical treatment of at least 3 months.

\section{Statistical analysis}

Categorical variables were evaluated by descriptive statistics using percentages. For continuous variables, mean and range were used. A risk assessment was performed with Mantel-Cox tests for corneal opacity requiring $\mathrm{PK}$ and age groups. $p<0.05$ value was considered statistically significant. All analyses were performed with Stata 14 software (Stata Corp, College Station, Texas, USA).

\section{Results}

During the 14 years analyzed, sixty penetrating PKs were performed. Three patients were excluded from the study due to lack of follow-up and only 57 patients were analyzed; two-thirds were male (63\%). From these patients, 47 underwent unilateral PK and 10 had bilateral PK, with an average of 1.6 years between each surgical procedure. The mean age at the time of surgery was 11 years (range 9 months to 18 years). The mean follow-up was 3.8 years. The most common indication for PK was keratoconus in 42 patients $(63 \%)$ followed by herpetic interstitial keratitis in 10 patients $(15 \%)$ and corneal dystrophies in seven patients (9\%) (Fig. 1).

The most frequent complication found was corneal rejection; 31 patients (54\%) had at least one rejection episode, of which $80 \%$ was satisfactorily resolved with topical steroid drop management. Patients younger than 9 years old presented earlier rejection compared with the other two groups of age $(p=0.023$, confidence

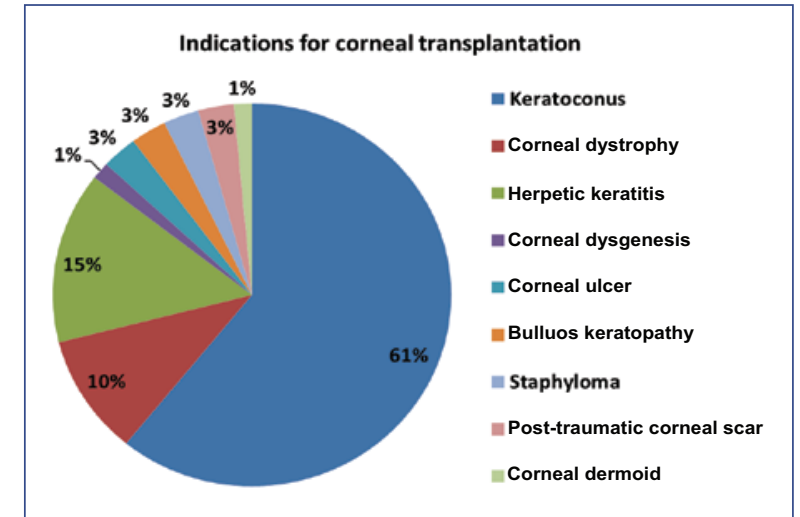

Figure 1. Indications for penetrating keratoplasty in children.

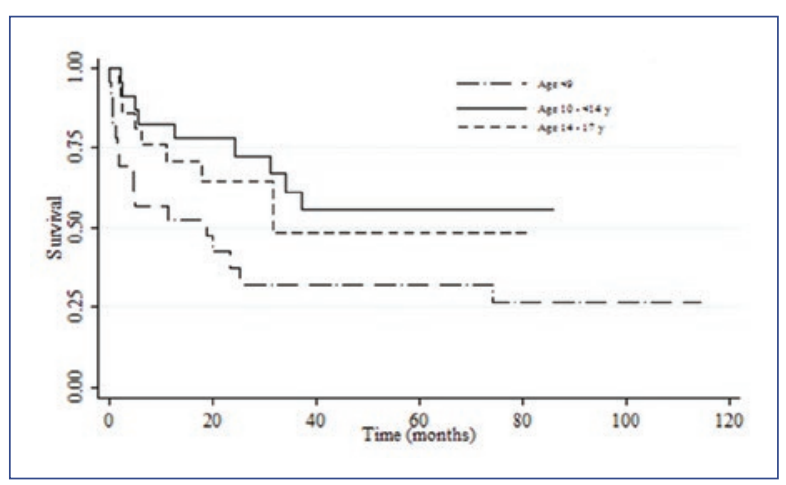

Figure 2. Kaplan-Meier graft survival plots showing the association between rejection and age. The survival curve of the group $<9$ years of age was significantly lower than the other age groups $(p<0.05)$.

interval [Cl] 95\% 0.17-0.87). Half of graft rejections occurred during the first 3 years after PK (Fig. 2). Patients with congenital opacities present more frequent and earlier rejection compared with keratoconus and herpetic keratitis ( $p=0.04, \mathrm{Cl} 95 \% 1.06-17.14)$. Graft rejection was frequent during the first 3 years after surgery (Fig. 3). The survival rate at 5 years for PK was $45.6 \% \quad(95 \% \mathrm{Cl} \quad 31.8-58.4$ months, standard deviation $=0.069$ ) with a 1-year survival rate of $70 \%$ (Fig. 4). Half of graft rejections occurred during the first 3 years after surgery; only in one patient had the rejection occurred 6 years after the PK. Five patients developed graft failure, which showed poor prognostic factors. No association was observed between gender, corneal rejections rate, and underlying systemic diseases with corneal failure. However, it should be noticed that most of these patients were younger than 9 years and poor 


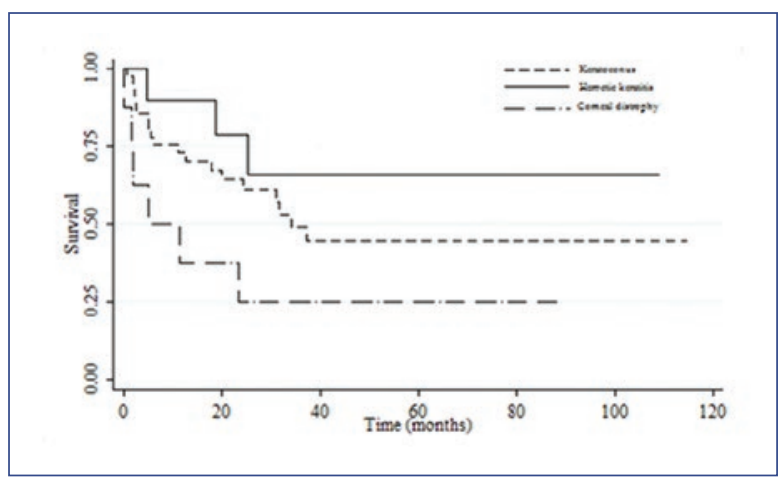

Figure 3. Kaplan-Meier graft survival plots showing the association between keratoconus, herpetic keratitis, and corneal dystrophy and penetrating keratoplasty rejection. Corneal dystrophies graft survival was significantly lower than keratoconus and herpetic keratitis $(p<0.05)$.

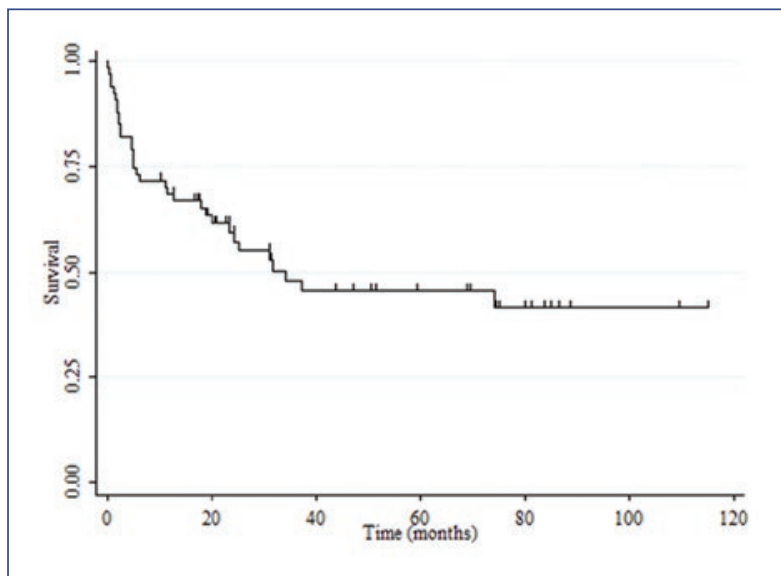

Figure 4. Kaplan-Meier survival curves of primary penetrating keratoplasty in Mexican pediatric patients.

prognoses such as delayed psychomotor development and secondary glaucoma (Table 1). One of these patients (patient 3) underwent a secondary PK.

\section{Discussion}

PK remains one of the most challenging corneal surgeries for the technical difficulties involved and the worse prognosis, at least in adult population ${ }^{10}$. Although the indications of PK in children are similar to those of adults $^{11}$, the visual prognosis depends on multiple factors such as etiology and age at the time of surgery ${ }^{12}$.

The pediatric graft survival rate in children is lower than in adults. Reports by Dana et al. showed a series of 164 pediatric PK with a survival rate of $80 \%$ per year and $67 \%$ at 2 years. In adults, the survival rate is $91 \%$ in the $1^{\text {st }}$ year and $72 \%$ at 5 years. Grafts performed for keratoconus were the most successful in terms of survival. McClellan et al. reported a success rate of $71 \%$ in a series of 19 pediatric $\mathrm{PK}^{13}$, consistent with the Australian Corneal Graft Registry results ${ }^{14}$, in which a 5-year survival rate for 4060 grafts performed for keratoconus was $89 \%$ at 10 years. The overall survival rate for this group of patients was $53 \%$ at 5 years of follow-up, possibly due to advanced atopic disease.

Congenital corneal opacities represent a high-risk factor for failure. Although some authors have found success rates higher than $50 \%{ }^{15}$, in the present study, a lower graft success was found in patients with corneal dystrophies (25\% at 80 months of follow-up) compared to Schaumberg's series, which was $71 \%$ graft survival rate $^{16}$. Two out of six of the patients with corneal dystrophies developed corneal failure in this study. Javadi et al. reported a $74 \%$ graft survival rate at 5 years for endothelial corneal dystrophy ${ }^{17}$. As reported elsewhere, a case of a corneal graft redo due to associated graft rejection and subsequent failure was observed in a patient with corneal dystrophy ${ }^{18}$.

This case series did not include any case of Peter's anomaly, although other authors have reported good functional results in those patients without glaucoma $^{19}$.

The limitations of the study are associated with the retrospective nature of the analysis and the lack of detailed standardized parameters such as type of donor, detailed pre-operative phenotyping, standardized follow-up, as well as suture removal registry. Furthermore, factors associated with a poor prognosis, such as treatment adherence and socioeconomically difficulties reflected as missing hospital appointments and trouble with following indications or getting medication, were not evaluated. Another limitation was the sample size: it was not possible to perform a multivariate analysis to determine association between age and corneal diseases with graft rejection because the stratified analysis of the three age groups showed that corneal dystrophies were only present in children younger than 9 years old, whereas herpetic keratitis and keratoconus were present in every analyzed age category (data not shown).

Although $50 \%$ of the studied population developed at least one episode of corneal graft rejection during the first 3 years of the follow-up, it resolved with topical steroid treatment in $80 \%$ of the cases, and patients maintained useful day to day vision. Only a sixth of the patients with corneal graft rejection ended up with graft failure that required a keratoplasty redo and systemic immunosuppression. 
Table 1. Clinical characteristics of patients who developed corneal failure

\begin{tabular}{|l|l|l|c|c|l|}
\hline Gender & & Associated eye disease & Age at surgery (years) & Corneal rejections & Systemic diseases \\
\hline 1 & F & Corneal ulcer & 6.8 & 2 & Severe dry eye \\
\hline 2 & M & Keratoconus & 16.9 & 1 & Developmental delay \\
\hline 3 & F & Corneal dystrophy & 2.8 & 2 & Secondary glaucoma \\
\hline 4 & F & Corneal ulcer & 2.9 & 1 & Developmental delay \\
\hline 5 & M & Corneal dystrophy & 9 & 3 & Secondary glaucoma \\
\hline
\end{tabular}

To summarize, a close follow-up of a pediatric PK patient is of significant importance, mostly during the first 3 years after surgery. Early identification of symptoms and signs of corneal graft rejection and immediate treatment could prevent corneal failure and subsequent corneal opacification. A larger patient cohort with a longer follow-up period would help for a better understanding of graft rejection and failure associated factors in pediatric keratoplasty patients.

Corneal transplantation can be successfully performed in many pediatric patients with keratoconus and herpetic keratitis. Although allograft rejection is widespread, it can be resolved successfully in almost all cases. Early identification of symptoms and signs of corneal graft rejection and prompt treatment could prevent corneal failure.

\section{Ethical disclosures}

Protection of human and animal subjects. The authors declare that no experiments were performed on humans or animals for this study.

Confidentiality of data. The authors declare that they have followed the protocols of their work center on the publication of data.

Right to privacy and informed consent. The authors declare that no patient data appear in this article.

\section{Conflicts of interest}

The authors declare that they have no conflicts of interest.

\section{Funding}

None.

\section{Acknowledgments}

The authors wish to thank optometrist Oswaldo Aguirre for his support elaborating on the database.

\section{References}

1. Zirm EK. Eine erfolgreiche totale Keratoplastik (A successful total keratoplasty). 1906. Refract Corneal Surg. 1989;5:258-61.

2. Lowe MT, Keane MC, Coster DJ, Williams KA. The outcome of corneal transplant in infants, children, and adolescents. Ophthalmology. 2011;118:492-7.

3. Vanathi M, Panda A, Vengayil S, Chaudhuri Z, Dada T. Pediatric keratoplasty. Surv Ophthalmol. 2009;54:245-71.

4. Lomholt JA, Baggesen K, Ehlers N. Recurrence and rejection rates following corneal transplantation for herpes simplex keratitis. Acta Ophthalmol Scand. 1995;73:29-32.

5. Ficker LA, Kirkness CM, Rice NS, Steele AD. Long-term prognosis for corneal grafting in herpes simplex keratitis. Eye (Lond). 1988;2:400-8.

6. Ariyasu RG, Silverman J, Irvine JA. Penetrating keratoplasty in infants with congenital glaucoma. Cornea. 1994;13:521-6.

7. AlArrayedh $\mathrm{H}$, Collum L, Murphy CC. Outcomes of penetrating keratoplasty in congenital hereditary endothelial dystrophy. $\mathrm{Br} \mathrm{J}$ Ophthalmol. 2018;102:19-25.

8. Panda A, Vanathi M, Kumar A, Dash Y, Priya S. Corneal graft rejection. Surv Ophthalmol. 2007;52:375-96.

9. Alldredge $\mathrm{OC}, \mathrm{Krachmer} \mathrm{JH}$. Clinical types of corneal transplant rejection. Their manifestations, frequency, preoperative correlates, and treatment. Arch Ophthalmol. 1981;99:599-604.

10. Limaiem R, Chebil A, Baba A, Ben Youssef N, Mghaieth F, El Matri L. Pediatric penetrating keratoplasty: indications and outcomes. Transplant Proc. 2011;43:649-51.

11. Dana MR, Moyes AL, Gomes JA, Rosheim KM, Schaumberg DA, Laibson PR, et al. The indications for and outcome in pediatric keratoplasty. A multicenter study. Ophthalmology. 1995;102:1129-38.

12. Karadag R, Chan TC, Azari AA, Nagra PK, Hammersmith KM, Rapuano CJ. Survival of primary penetrating keratoplasty in children. Am J Ophthalmol. 2016;171:95-100.

13. McClellan K, Lai T, Grigg J, Billson F. Penetrating keratoplasty in children: visual and graft outcome. Br J Ophthalmol. 2003;87:1212-4.

14. Kelly TL, Williams KA, Coster DJ, Australian Corneal Graft Registry. Corneal transplantation for keratoconus: a registry study. Arch Ophthalmol. 2011;129:691-7.

15. Michaeli A, Markovich A, Rootman DS. Corneal transplants for the treatment of congenital corneal opacities. J Pediatr Ophthalmol Strabismus. 2005;42:34-44.

16. Schaumberg DA, Moyes AL, Gomes JA, Dana MR. Corneal transplantation in young children with congenital hereditary endothelial dystrophy. Multicenter pediatric keratoplasty study. Am J Ophthalmol. 1999;127:373-8.

17. Javadi MA, Baradaran-Rafii AR, Zamani M, Karimian F, Zare M, Einollahi $B$, et al. Penetrating keratoplasty in young children with congenital hereditary endothelial dystrophy. Cornea. 2003;22:420-3.

18. Bersudsky V, Blum-Hareuveni T, Rehany $\mathrm{U}$, Rumelt $\mathrm{S}$. The profile of repeated corneal transplantation. Ophthalmology. 2001;108:461-9.

19. Zaidman GW, Flanagan JK, Furey CC. Long-term visual prognosis in children after corneal transplant surgery for Peters anomaly Type I. Am J Ophthalmol. 2007;144:104-8. 